\title{
FATAL ENTERITIS IN A TIGER CAUSED BY PHYSALOPTERA PRAEPUTIALIS.
}

\author{
BY A. J. HARRISON, M.B. \\ Consulting Physician to the Bristol General Hospital, \\ AND I. WALKER HALL, M.D., \\ Professor of Pathology, University College, Bristol, and Pathologist \\ to the Royal Infirmary, Bristol.
}

A MaLe Malay tiger was brought to the Clifton Zoological Gardens in July, 1908. He was then very thin and fed badly. After a time he settled down in his new quarters, and ate his food with greater relish. He appeared to be in good health and his coat was sleek and fine, but he never jumped or played in the usual way of his species. On February 4th he vomited, and had a severe attack of diarrhoea. His breathing became less abdominal and more thoracic in character, and death occurred two days later.

The post-mortem examination showed that the animal had been well nourished and that death was due to enteritis caused by round worms. Owing to the kindness of Messrs A. E. Shipley and R. T. Leiper the causal parasite has been identified as Physaloptera praeputialis. This nematode has been fully described by von Linstow (1888).

\section{Autopsy.}

On opening the abdominal cavity, a round worm, measuring about $1 \frac{1}{2}$ inches by $1 / 8$-inch, was seen coiled up just under the serous capsule of the liver. Calcified areas, corresponding in size to that of the parasite mentioned, were present in the subcapsular tissues of the spleen. Under the serous coat of the stomach, intestine and colon, a number of well-marked swellings were seen; these were arranged irregularly and varied considerably in size and shape. Some of them 
formed a segment of a circle, others were cone-shaped, others again had the appearance of an elongated cone and at the tip of the cone there was sometimes a "pin-point" orifice. All the swellings were uniformly hard and anaemic; their borders were well-defined, and they appeared to be seated in the muscular structures. The overlying serosa was not the seat of any exudative process; there was a little thickening of the subendothelial tissues but there were no signs of adhesions. The process showed the signs of chronicity and was apparently enterogenous in origin.

When the stomach and intestines were opened up, similar nodules projected into the lumen of the canal. In this case they were covered by the mucosa; at or about the centre of the raised area, however, the mucous coat was deficient, leaving an aperture which communicated with the interior of the nodule.

In the stomach the nodules were few in number but large in size; in the small intestines they were more numerous, of medium size, and subserous rather than submucous; in the large intestine there were so many that they practically occupied the entire area, being separated from one another by a small area of lymphoid tissue only.

The whole alimentary tract was in a condition of advanced catarrhal inflammation, and in the lumen large numbers of the worms were present.

When the nodules were bisected, they were found to consist of dense fibrous tissue surrounding an irregularly branching lumen. In the lumen a number of small worms were seen. Microscopical examination showed that each of the young worms was surrounded by bands of very dense fibrous tissue, and that the fibrosis was less marked towards the periphery of the mass; the peri-nodal tissues showed but slight proliferative changes.

The general appearances suggested that the female worm burrowed tbrough the mucosa and deposited embryos in the submucosal tissues. During the development of the worms a fibrous nodule was formed, and the nodule extended into the muscular layer causing considerable atrophy of the muscle fibres, and in some cases reached the subserous tissues. In the latter instance, when the young worm happened to lie immediately beneath the serosa or was cut off from the intestinal aperture by fibrous tissue, it commenced to burrow and so reached intraperitoneal organs, such as the liver and spleen. When, however, the worm was in a position to utilize the opening into the alimentary canal it emerged from the nodule, buried its head in mucosal tissue and 


\section{A. J. Harrison and I. W. Hall}

so commenced its enterogenous parasitic life. These lesions are somewhat similar to those described by von Linstow (1879).

The widespread distribution of the worms and the extensive chronic irritation of the gastric and intestinal wall were quite sufficient to account for the death of the animal.

The lungs were riddled with cysts containing the Paragonimus westermani (Kerb); there was but little peri-cystic consolidation or signs of marked interference with pulmonary functions. The other organs were normal.

\section{REFERENCES.}

Von Linstow (1879). Archiv für Naturgeschichte, p. 181.

- (1888). Ibid. p. 239. 